\title{
Gain recovery dynamics and limitations in quantum dot amplifiers
}

Berg, Tommy Winther; Bischoff, Svend; Magnúsdóttir, Ingibjörg; Mørk, Jesper; Borri, Paola

Published in:

Proceedings on Technical Digest Lasers and Electro-Optics

Link to article, DOI:

10.1109/CLEO.2001.947910

Publication date:

2001

Document Version

Publisher's PDF, also known as Version of record

Link back to DTU Orbit

Citation (APA):

Berg, T. W., Bischoff, S., Magnúsdóttir, I., Mørk, J., \& Borri, P. (2001). Gain recovery dynamics and limitations in quantum dot amplifiers. In Proceedings on Technical Digest Lasers and Electro-Optics (pp. 358-359) https://doi.org/10.1109/CLEO.2001.947910

\section{General rights}

Copyright and moral rights for the publications made accessible in the public portal are retained by the authors and/or other copyright owners and it is a condition of accessing publications that users recognise and abide by the legal requirements associated with these rights.

- Users may download and print one copy of any publication from the public portal for the purpose of private study or research.

- You may not further distribute the material or use it for any profit-making activity or commercial gain

- You may freely distribute the URL identifying the publication in the public portal 


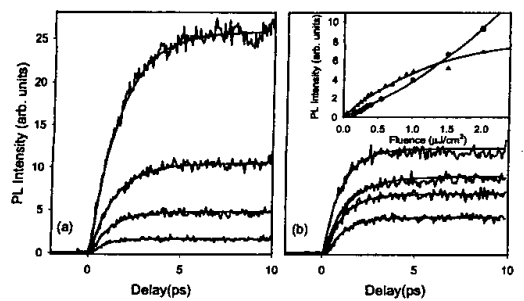

CWK5 Fig. 3. Time-resolved PL for the firstexcited state (a) and ground state (b) of sample C $(\Delta \mathrm{E}-66 \mathrm{meV})$ for the following fluences, $0.5 \mu \mathrm{J} / \mathrm{cm}^{2}, 1.0 \mu \mathrm{J} / \mathrm{cm}^{2}, 3.0 \mu \mathrm{J} / \mathrm{cm}^{2}$ and $10.1 \mu \mathrm{J} / \mathrm{cm}^{2}$. Note that the ground-state emission saturates, while the excited-state emission continues to increase with fluence. The solid lines are mono-exponential fits, which yield time constants of less than $2 \mathrm{ps}$ in all cases. The inset shows fluence dependence of the first-excited state (dots) and the ground state (triangle) emission.

Figure 3 illustrates the transient behavior of both the first excited-state and the ground-state emission from sample $\mathrm{C}$ at $12 \mathrm{~K}$. The excited-state emission is observed even for very low excitation levels, well below that for which the ground state of all of the dots is filled. The rise time for the excited state is comparable to that of the ground state, but the lifetime (not shown) of $210 \mathrm{ps}$ is only half that of the ground state $(450 \mathrm{ps})$. In addition, while the time-resolved PL intensity for the ground state initially increases linear with excitation fluence, the excited-state displays a quadratic intensity dependence (Fig. 3). These observations suggest that the excited-state emission arises only from dots already containing a ground-state exciton, a result that is consistent with ultrafast interlevel relaxation and a random capture process. ${ }^{4}$

\section{References}

1. R. Heitz, M. Veit, N.N. Ledentsov, A. Hoffmann, D. Bimberg, V.M. Ustinov, P.S. Kop'ev, and $\mathrm{Zh}$. I. Alferov, "Energy relaxation by multiphonon process in InAs/GaAs quantum dots," Phys. Rev. B Vol. 56, 10435 (1997).

2. H. Benisty, C.M. Sotomayor-Torres, and C. Weisbuch, "Intrinsic mechanism for the poor luminescence properties of quantumbox systems," Phys. Rev. B 44, 10945 (1991).

3. U. Bockelmann, "Excition relaxation and radiative recombination in semiconductor quantum dots," Phys. Rev. B 48, 17637 (1993).

4. M. Grundmann and D. Bimberg, "Theory of random population for quantum dots," Phys. Rev. B 55, 9740 (1997).
CWK6

6:00 pm

Gain recovery dynamics and limitations in quantum dot amplifiers

Tommy.W. Berg, Svend Bischoff, Ingibjorg Magnusdottir, Jesper Mørk, Paola Borri, ${ }^{*}$ Research Center COM, Technical University of Denmark, Build, 345V, DK-2800 Kgs. Lyngby, Denmark; E-mail: twb@com.dtu.dk; ${ }^{*}$ Lehrstuhl für Experimentelle Physik EIIb, Universität Dortmund, Germany

While ultra-low threshold current densities have been achieved in quantum dot (QD) lasers, the predicted potential for high-speed modulation has not yet been realized despite the high differential gain. Furthermore, recent single pulse experiments demonstrated very fast gain recovery in a quantum dot amplifier, ${ }^{1}$ and it is thus not yet clear what the limiting processes for the device response are. We present here the results of a comprehensive theoretical model, which agrees well with the experimental results, and indicates the importance of slow recovery of higher energy levels.

The model used is of the rate-equation type with three energy levels: ground state (GS) and excited state (ES) dot levels and a wetting layer

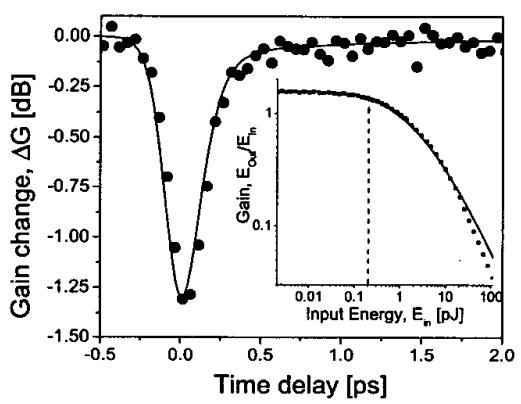

CWK6 Fig. 1. Measured pump probe response of the amplifier in the gain regime (dots) and corresponding numerical result (solid line). The insert compares the measured (squares) and calculated (solid line) saturated single pulse gain as function of input pulse energy. The dashed arrow indicates the pump pulse energy used in the pump-probe experiment.

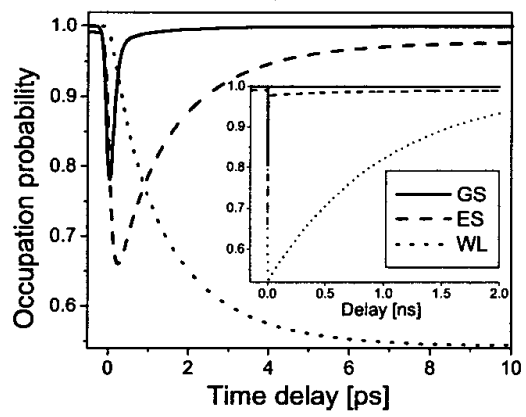

CWK6 Fig. 2. Occupation probability as function of time for the ground state (GS), excited state (ES) and wetting layer (WL) of the QDamplifier, when a $150 \mathrm{fs}$ pump pulse is injected at time delay zero. The insert shows the long-term changes.

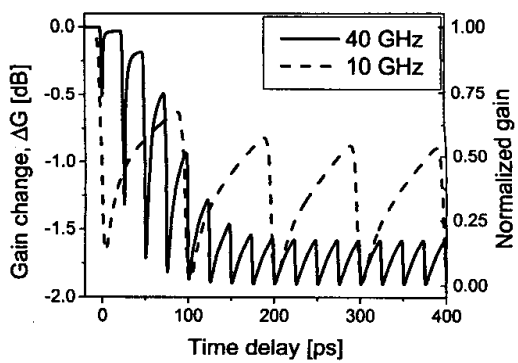

CWK6 Fig. 3. Gain change under injection of a periodic train of short pulses with a repetition rate of $40 \mathrm{GHz}$ (solid line) and $10 \mathrm{GHz}$ (dotted line). The right-hand side axis shows the normalized gain with 1 corresponding to maximum saturated gain and 0 corresponding to transparency.

(WL) level. Both Auger and phonon assisted relaxation and excitation effects are taken into account and are related through a quasi-equilibrium condition. All results have been verified with a master-equation model of the type suggested in. $^{2}$

Fig. 1 shows the experimental and numerical pump-probe response of the QD-amplifier used in $^{1}$ in the saturated gain regime. The gain recovers nearly completely in less than $0.5 \mathrm{ps}$, which is significantly faster than any other type of devices.

The explanation for the fast gain recovery can be seen in Fig. 2. As carriers from the GS-level are removed through stimulated emission, ES-level carriers relax quickly to the GS-level on a timescale of a few hundred femtoseconds. The ES-level thus acts as a nearby carrier reservoir for the GS-level allowing for the ultrafast gain recovery. The process of carrier capture is slower than intra-dot relaxation and, therefore, the ES-level recovers on a longer time-scale of several picoseconds.

The slow refilling of the ES-level means that the ultrafast gain recovery will not continue for consecutive pulses (see Fig. 3). For the $40 \mathrm{GHz}$ signal the gain recovers almost completely after the first pulse, but hereafter continues to decrease after each pulse until only small deviations from transparency are observed. The device is clearly not able to sustain a pulse train at this bit rate despite the fast initial gain recovery. For the $10 \mathrm{GHz}$ signal an initial gain decrease is observed, but then the dynamics stabilizes and the gain recovers repeatedly to half of the initial value.

Directly modulated QD-lasers have been reported with room temperature bandwidths of $5-6 \mathrm{GHz},{ }^{3}$ which is comparable to the $10 \mathrm{GHz}$ signal in Fig. 3. The effects of slow carrier recovery, illustrated above, will limit both lasers as well as amplifiers for all-optical signal processing.

In conclusion, ultrafast gain recovery in quantum dot amplifiers is possible due to excited states acting as reservoir for the ground state-level. It is thus not the recovery time of the ground state, but rather the recovery times of the excited states and the wetting layer, which limit the performance. The reduction of the recovery time of these upper levels is a key point for increasing the speed of QD devices. One improvement in this respect might be an overgrowth layer, which has been shown to increase the capture efficiency. ${ }^{4}$

1. P. Borri, W. Langbein, J.M. Hvam, F. Heinrichsdorff, M.-H. Mao, and D. Bimberg, "Ul- 
trafast Gain Dynamics in InAs-InGaAs Quantum-Dot Amplifiers," IEEE Photon. Technol. Lett. 12, 594-596 (2000).

2. M. Grundmann, R. Heitz, D. Bimberg J.H.H. Sandmann and J. Feldmann, "Carrier Dynamics in Quantum Dots: Modeling with Master Equations for the Transitions between Micro-States," Phys. Stat. Sol. (b) 203, 121-132 (1997).

3. P. Bhattacharya, D. Klotzkin, O. Qasaimeh, W. Zhou, S. Krishna, and D. Zhu, "HighSpeed Modulation and Switching Characteristics of $\operatorname{In}(\mathrm{Ga}) \mathrm{As}-\mathrm{Al}(\mathrm{Ga})$ As Self-Organized Quantum-Dot Lasers," IEEE J. Quantum Electron. 6(3), 426-438 (2000).

4. F. Heinrichsdorff, M.-H. Mao, N. Kirstaedter, A. Krost, D. Bimberg, A.O. Kosogov, and P. Werner, "Room-temperature continous-wave lasing from stacked InAs/GaA quantum dots grown by metalorganic chemical vapor deposition," Appl. Phys. Lett. 71(1), 22-24 (1997).

\section{cWK7}

$6: 15 \mathrm{pm}$

Demonstration of passive Q-switching and passlve mode-locking in $1.3 \mu \mathrm{m}$, twosection InAs quantum dot lasers

Xiaodong Huang, A. Stintz, Hua Li, L.F. Lester, Julian Cheng, K.J. Malloy, Center for High Technology materials, University of New Mexico, 1313 Goddard SE, Albuquerque, NM87106; Email:xdhuang@chtm.chtm.unm.edu

The properties of quantum dot (QD) layers as absorbers in an active device have not been investigated in detail. In this paper, we describe the bistable operation of a long-wavelength, oxideconfined, two-section quantum dot laser with an integrated QD saturable absorber. Our structure exhibits passive Q-switching and passive modelocking.

The devices were fabricated from the same wafer as described in Refs. [1] and [2] with a 50 $\mu \mathrm{m}$ gap in the top p-type contact metals. The laser section and the absorber section are $\mathrm{L}_{\mathrm{g}}=$ $4.73 \mathrm{~mm}$ and $\mathrm{L}_{\mathrm{a}}=0.85 \mathrm{~mm}$ long, respectively. Current confinement is provided by the lateral wet oxidation of a $50 \mathrm{~nm}$ thick $\mathrm{Al}_{0.98} \mathrm{Ga}_{0.02}$ As layer, giving a current aperture of $10 \mu \mathrm{m}$. The cleaved facets were uncoated and the devices were mounted p-side up on a copper heat sink and tested at room temperature.

DC characteristics were measured with cur-

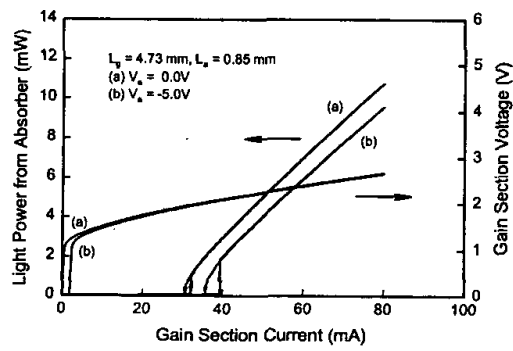

CWK7 Fig. 1. Room temperature lasing and electrical characteristics of a two-section $Q D$ laser with (a) $\mathrm{V}_{\mathrm{a}}=0.0 \mathrm{~V}$, and (b) a reverse bias of $V_{a}=-5.0 \mathrm{~V}$, applied to the absorber section.

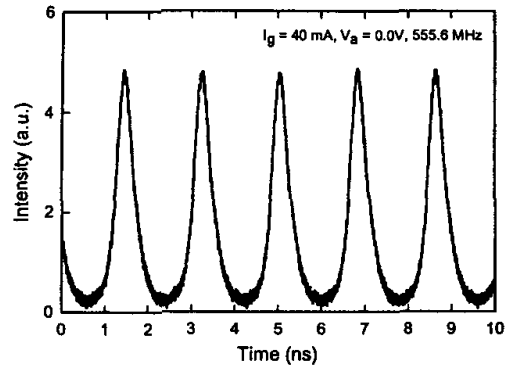

CWK7 Fig. 2. Q-switching pulse train under bias condition of $I_{b}=40 \mathrm{~mA}, V_{a}=0.0 \mathrm{~V}$ for a modulation frequency of $555.6 \mathrm{MHz}$. The pulsewidth is about 450 ps.

rent injection $\left(\mathrm{I}_{\mathrm{g}}\right)$ into the gain section and constant reverse bias voltage $\left(\mathrm{V}_{\mathrm{a}}\right)$ applied to the absorber section. Lasing occurred on the ground state $(\lambda=1278 \mathrm{~nm})$. Figure 1 shows the variation in lasing light power (L) emitted from the absorber facet and the voltage $\left(V_{g}\right)$ across the laser section with the forward and backward sweep of the laser current under (a) $\mathrm{V}_{\mathrm{a}}=0.0 \mathrm{~V}$, and (b) with $\mathrm{V}_{\mathrm{a}}=-5.0 \mathrm{~V}$ across the absorber section. The L-I characteristics exhibit clear counterclockwise hysteresis loops and bistability. The physical origin of the bistability will be discussed.

To observe $\mathrm{Q}$-switching operation, a constant current superimposed with a square wave modu lation signal was applied to the gain section via bias tee, while a constant reverse bias was applied to the absorber. Q-switching up to $1 \mathrm{GHz}$ was achieved. The narrowest pulsewidth was $330 \mathrm{ps}$ for modulation at $294 \mathrm{MHz}$. Q-switching pulse parameters, pulsewidth, peak power, and turnon delay vary with the gain section current. Fig ure 2 shows the pulse train obtained under optimum bias condition for a modulation signal of 555.6 $\mathrm{MHz}$. The modulation depth decreases with increasing modulation frequency. Spectral broadening was observed associating with the Qswitching. Possible reasons for the wide Qswitching pulsewidth will be presented.

Mode-locking at $7.4 \mathrm{GHz}$ was achieved when both the gain and absorber sections of the lasers were dc biased. The mode-locking pulsewidth was measured using collinear autocorrelation. Figure 3 shows how the autocorrelation varies with the gain section current at an absorber bias of $-4.0 \mathrm{~V}$. Full mode-locking was achieved for

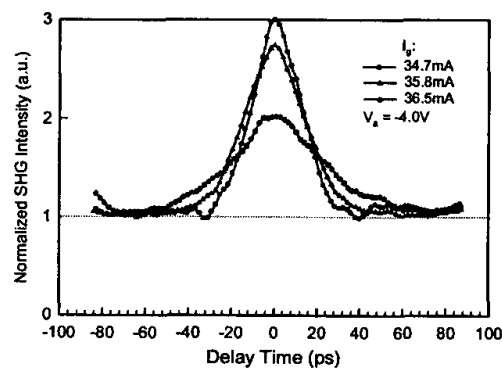

CWK7 Fig. 3. Autocorrelation trace for different gain section current at absorber reverse bias of $-4.0 \mathrm{~V}$. The best mode-locking occurs in side the bistable region. gain section currents close to the lower hysteresis threshold. The corresponding pulsewidth is about 17 ps assuming a hyperbolic secant squared pulse, and the optical spectral bandwidth was measured to be about $1 \mathrm{~nm}$. The timebandwidth product is about 3.1, more than 6 times of the transform limit, and suggests the presence of phase modulation. The modulation depth of the mode-locked pulse decreases as the gain current increases. No self-pulsation was observed as verified by the electrical spectrum of the mode-locked laser output.

In conclusion, we report the demonstration of passive Q-switching and passive mode-locking in bistable, oxide-confined, two-section, $1.3 \mu \mathrm{m}$ quantum dot lasers.

\section{References}

1. Xiaodong Huang, A. Stintz, C.P. Hains, G.T. Liu, J. Cheng and K.J. Malloy, "Efficient high temperature CW lasing operation of oxideconfined long-wavelength InAs quantum dot lasers," Electron. Lett., 36, 41-42 (2000).

2. L.F. Lester, A. Stintz, H. Li, T.C. Newell, E.A. Pease, B.A. Fuchs, K.J. Malloy, "Optical characteristics of $1.24 \mu \mathrm{m}$ InAs quantum dot laser diodes," IEEE Phot. Tech. Lett., 11, 931-933 (1999)

CWL

4:45 pm-6:30 pm Room: 321-323

\section{Spectroscopic Approaches for Biomedical Diagnostic}

Amir H. Gandjbakche, National Inst. of Health, USA, Presider

CWL1

4:45 pm

5-D fluorescence Imaging using an all-solidstate diode-pumped laser system

D.S. Elson, S.E.D. Webb, J. Siegel, S. LevequeFort, D. Parsons-Karavassilis, M.J. Cole, P.M.W. French, M. Hopkins, ${ }^{*}$ M.J. Lever, ${ }^{\star *}$ L.O.

Sucharov, ${ }^{\dagger}$ M.A.A. Neil, ${ }^{\dagger}$ R. Juškaitis ${ }^{\dagger}$ T. Wilson, ${ }^{\dagger}$ Femtosecond Optics Group, Physics Dept., Imperial College, London SW7 2BW, U.K.; email: paul.french@ic.ac. $u k$; ${ }^{\star}$ Optical Insights, 1807 2nd St., Suite \#60, Santa Fe, NM 87505; email:mhopkins@optical-insights.com **Department of Biological and Medical Systems, Imperial College, London SW7 2BY, U.K. Tel: $44-$ 20-7594 5172, m.j.lever@ic.ac.uk; ${ }^{\dagger}$ Department of Engineering Science, University of Oxford, Parks Road, Oxford OXI 3PJ, U.K.; email: tony.wilson@eng.ox.ac.uk

Fluorescence is widely used in biomedicine and other applications both to track specific fluorophores and study anatomical features. Fluorescence lifetime measurements add functional information because they are dependent on the local environment of the fluorophores (e.g. oxygen, $\left[\mathrm{Ca}^{2+}\right], \mathrm{pH}$ etc.) e.g.. ${ }^{1}$ Fluorescence Lifetime Imaging (FLIM) is particularly exciting since it can exploit this feature to provide non-invasive functional/diagnostic imaging. Compiementary functional information may be obtained using spectrally-resolved fluorescence imaging. ${ }^{2}$ In or- 